\title{
Envolvimento dos Alunos em Atividades de Modelagem Matemática: relação com o saber e possibilidades de ação
}

\section{Students' Involvement in Mathematical Modelling Activities: relationship to knowledge and possibilities of action}

\author{
Ilaine da Silva Campos* \\ Jussara de Loiola Araújo**
}

\begin{abstract}
Resumo
Apresentamos, neste artigo, resultados de uma investigação que buscou compreender o envolvimento de dois alunos, integrantes de um grupo, em uma atividade de modelagem matemática, a partir da relação que eles estabelecem com o saber matemático. Apoiadas no referencial teórico de Bernard Charlot, da relação com o saber, e utilizando uma abordagem qualitativa, analisamos três episódios em que o grupo está desenvolvendo um projeto de modelagem matemática. Além dos episódios, entrevistas possibilitaram entender aspectos referentes ao envolvimento dos alunos. Nossa análise deu origem à construção do conceito de possibilidades de ação. Como resultado, percebemos que a relação de cada aluno com a Matemática desempenha um papel decisivo em suas possibilidades de ação e que seu envolvimento em atividades de modelagem pode ser compreendido não apenas como as ações efetivamente realizadas, mas também como as possibilidades de ação vislumbradas por eles.
\end{abstract}

Palavras-chaves: Educação Matemática. Modelagem Matemática. Prática dos Alunos. Matematização. Abordagem Qualitativa.

\begin{abstract}
In this paper, we present the results of an investigation that sought to understand the involvement of two students, members of a group, in a mathematical modelling activity, based on the relationship that they have established with mathematical knowledge. Supported by Bernard Charlot's theoretical framework - the relationship to knowledge - and using a qualitative approach, we analysed three episodes in which the group is developing a modelling project. Besides the episodes, interviews promoted a deep understanding of aspects related to the students' involvement. Our analysis gave rise to the construction of the concept of possibilities of action. As a result, we noticed that the relationship of each student to mathematical knowledge plays a decisive role in his/her possibilities of action and that students' involvement in modelling activities can be understood not only as the actions effectively performed by them, but also as the possibilities of action that they glimpse.
\end{abstract}

Key words: Mathematics Education. Mathematical Modelling. Students’ practice. Mathematization. Qualitative Approach.

\footnotetext{
* Doutoranda pelo Programa de Pós-Graduação em Educação da Universidade Federal de Minas Gerais (UFMG). Licenciatura em Matemática pela Universidade Estadual de Feira de Santana (UEFS) e Mestrado em Educação pela Universidade Federal de Minas Gerais (UFMG). E-mail: ila_scampos@yahoo.com.br

** Doutora em Educação Matemática, Universidade Estadual Paulista (UNESP). Professora do Departamento de Matemática e do Programa de Pós-Graduação em Educação da Universidade Federal de Minas Gerais (UFMG), Belo Horizonte, Minas Gerais, Brasil. Endereço para correspondência: Departamento de Matemática - UFMG, Av. Presidente Antônio Carlos, 6627, Pampulha, CEP: 31270901, Belo Horizonte, Minas Gerais, Brasil. E-mail: jussara@mat.ufmg.br
} 


\section{Introdução}

Na Educação Matemática existe uma multiplicidade de abordagens práticas, concebidas nos contextos escolares e, dentre elas, a modelagem matemática. Essa tendência tem ganhado destaque nas pesquisas no campo da Educação Matemática, sendo abordada a partir de diversos olhares teóricos e objetivos referentes às práticas em sala de aula (KAISER; SRIRAMAN, 2006).

Neste artigo, assumimos a concepção de Barbosa (2007a), segundo a qual a modelagem matemática, na Educação Matemática, é um ambiente de aprendizagem ${ }^{1}$ em que os alunos são convidados a investigar, por meio da Matemática, situações com referência na realidade. Essa concepção destaca que os alunos são convidados a participarem, o que implica em adquirirem responsabilidade pelo processo de investigação. Ou seja, os alunos estão no centro da ação pedagógica no desenvolvimento de atividades dessa natureza.

A participação (ou a prática) dos alunos nesses ambientes de aprendizagem é o foco deste artigo. Nosso objetivo é compreender o envolvimento de dois alunos, integrantes de um grupo, em uma atividade de modelagem ${ }^{2}$, a partir de suas relações com o saber matemático, entendidas no sentido da relação com o saber de Bernard Charlot.

Para tal, começamos, na próxima seção, com a apresentação de alguns trabalhos que versam sobre as práticas dos alunos em ambientes de modelagem e do referencial teórico de Charlot (2000) sobre a relação com o saber. Na seção seguinte, trazemos informações sobre os sujeitos e o contexto deste estudo e sobre a organização da atividade de modelagem. Na seção 4, discutimos a abordagem metodológica. Em seguida, apresentamos três episódios ocorridos durante o desenvolvimento da atividade, assim como uma análise desses episódios. Como consequência da análise, propomos a ideia de possibilidades de ação, como um constructo teórico para ajudar a compreender o envolvimento dos alunos em ambientes de aprendizagem de modelagem.

\section{Práticas dos alunos em ambientes de modelagem e a relação com o saber}

As discussões sobre modelagem na Educação Matemática têm, como um de seus focos de debate, as práticas dos alunos no desenvolvimento de atividades dessa natureza (ARAÚJO; BARBOSA, 2005; MAAß, 2005; OLIVEIRA; BARBOSA; SANTANA, 2009). Tais discussões levantam questionamentos sobre a relação entre as práticas dos alunos e as especificidades da modelagem.

Araújo e Barbosa (2005) discutem o caso de um grupo de alunas que decidiu inventar uma situação fictícia na qual os dados correspondiam, exatamente, a uma função previamente escolhida, percorrendo um caminho inverso ao que se propõe normalmente para a modelagem. Os autores denominaram tal ação de estratégia inversa.

\footnotetext{
${ }^{1}$ Ambiente de aprendizagem (SKOVSMOSE, 2000) inclui desde elementos logísticos, relacionados à organização do tempo e do espaço escolar, os materiais utilizados, até a concepção filosófica que fundamenta a atividade.

${ }^{2}$ Quando utilizarmos apenas a palavra modelagem, estamos nos referindo à modelagem matemática na Educação Matemática.
} 
Maaß (2005), por sua vez, defende que as crenças que os estudantes têm em relação à Matemática interferem na maneira como eles se comportam em atividades de modelagem e na aquisição de competências em modelagem. Para Maaß (2005), essas crenças podem se caracterizar como barreiras na inserção da modelagem nas práticas dos alunos. Já Oliveira, Barbosa e Santana (2009) discutem a resistência de um grupo de alunos em desenvolver uma atividade de modelagem. Para eles, a atividade causou um estranhamento aos alunos, visto que se caracterizou como um ambiente atípico às aulas de Matemática.

A análise desses estudos (ARAÚJO; BARBOSA, 2005; MAAß, 2005; OLIVEIRA; BARBOSA; SANTANA, 2009) aponta entendimentos sobre o que pode acontecer quando os alunos desenvolvem atividades de modelagem. Eles nos apresentam a importância de se buscar entender como se dá o envolvimento dos alunos em atividades de modelagem. Esses três estudos destacam, de uma forma ou outra, que o envolvimento dos alunos em atividades de modelagem é marcado pelo que acontece em suas aulas de Matemática.

Skovsmose (2000) destaca que ambientes de aprendizagem em que os alunos são convidados a investigar, como é o caso da compreensão de modelagem aqui adotada, são ainda pouco frequentes nas salas de aula de Matemática. Por isso, entendemos que uma atividade de modelagem pode representar uma mudança de paradigma em relação ao que os alunos percebem como comum às aulas de Matemática. Acreditamos, então, que considerar a relação com o saber matemático (CHARLOT, 2000) é algo que merece nossa atenção, para compreendermos aspectos que envolvem as práticas dos alunos em atividades dessa natureza.

A relação com o saber é conceituada por Charlot (2000) a partir de uma proposição básica: é uma forma de relação do sujeito com o mundo. Esse conceito foi desenvolvido a partir do objetivo de construir uma sociologia do sujeito, dando destaque à importância de se compreender cada sujeito como um ser singular. Charlot (2000) entende que o sujeito está em relação com o meio, que é o mundo partilhado por esse sujeito com outros sujeitos. Dessa forma, o sujeito não está situado em um ambiente de maneira que este exerça uma ação sobre ele, mas sim, o sujeito está em relação com um meio.

A relação com o saber é compreendida como "a relação de um sujeito com o mundo, com ele mesmo e com os outros. É a relação com o mundo como conjunto de significados, mas também, como espaço de atividades, e se inscreve no tempo" (CHARLOT, 2000, p. 78; grifos do autor).

Charlot (2000) explica que o conjunto de significados é a maneira como o sujeito percebe, imagina e pensa o mundo, por meio do que deseja e do que sente. Esse conjunto de significados é partilhado com outros sujeitos. Além disso, o mundo é, também, horizonte de atividades. E o aprender requer tempo e jamais acaba. Esse tempo se desenvolve em três dimensões: presente, passado e futuro. $\mathrm{O}$ aprender é entendido como "a apropriação do mundo, a construção de si mesmo e a inscrição em uma rede de relações com os outros” (p. 78). Ainda de acordo com esse autor, "analisar a relação com o saber é estudar o sujeito confrontado à obrigação de aprender, em um mundo que ele partilha com outros" (p. 79). 
Apoiadas em Charlot (2000), buscaremos analisar e gerar compreensões acerca do envolvimento de dois alunos em atividades de modelagem. Esses alunos, sujeitos deste estudo, são apresentados a seguir, assim como o contexto em que o estudo foi realizado.

\section{Sujeitos e contexto do estudo e organização da atividade de modelagem}

Os estudantes, sujeitos deste estudo, eram alunos da disciplina Matemática A, componente da grade curricular do primeiro período do curso de Gestão Pública, em nível de graduação, da Universidade Federal de Minas Gerais (UFMG). Tal curso é ofertado pela Faculdade de Filosofia e Ciências Humanas (FAFICH) e tem suas atividades desenvolvidas no turno da noite, no campus da Pampulha, na Cidade de Belo Horizonte.

A disciplina Matemática A, sob responsabilidade do Departamento de Matemática, do Instituto de Ciências Exatas (ICEx), da UFMG, tem uma ementa que visa abordar os conteúdos de funções, derivadas e integrais, com carga horária de 60 horas, cumprida em um semestre letivo. No período que corresponde a este estudo (segundo semestre de 2011), constava um total de 67 alunos matriculados em uma turma da referida disciplina que tinha, como docente responsável, a segunda autora deste artigo ${ }^{3}$.

O desenvolvimento de projetos de modelagem foi proposto pela professora como uma das atividades da disciplina. Dos 100 pontos distribuídos entre as avaliações da disciplina, 40 foram destinados para a avaliação dos projetos de modelagem. A organização de tais projetos, pela professora, pressupõe a seguinte compreensão:

uma abordagem, por meio da matemática, de um problema não-matemático da realidade, ou de uma situação não-matemática da realidade, escolhida pelos alunos reunidos em grupos, de tal forma que as questões da Educação Matemática Crítica embasem o desenvolvimento do trabalho. (ARAÚJO, 2002, p. 39)

A partir da escolha dos temas pelos próprios alunos, eles se organizaram em nove grupos, cada um composto por um número de alunos que variava entre cinco e oito. Para orientar os alunos no desenvolvimento dos projetos, a professora contou com a colaboração de sete tutores-orientadores ${ }^{4}$, entre eles a primeira autora deste artigo. A professora criou um espaço no Moodle $^{5}$ para cada grupo, nos quais os tutores-orientadores e os alunos poderiam se comunicar. Cada grupo desenvolveu uma dinâmica própria com seu tutor-orientador e a professora não interferiu nessa dinâmica no decorrer do desenvolvimento dos projetos. Os projetos de modelagem foram avaliados em três momentos durante seu desenvolvimento:

- $1^{\circ}$ momento: A elaboração de um plano inicial, no início do semestre, com o peso de 5 pontos, no qual os alunos apresentaram uma proposta de pesquisa para o desenvolvimento da atividade de modelagem. A professora o avaliou apontando contribuições para o desenvolvimento do trabalho;

\footnotetext{
${ }^{3}$ Tendo em vista o objetivo desta seção, algumas vezes a segunda autora deste artigo será tratada como a professora e a primeira autora como pesquisadora ou tutora-orientadora. Sobre esta última denominação, serão apresentadas informações a seguir. Os mesmos tratamentos estão presentes nas próximas seções.

${ }^{4}$ Orientandos da professora, no âmbito da iniciação científica, mestrado ou doutorado.

5 Ambiente virtual de aprendizagem que é adotado na UFMG como o espaço virtual das disciplinas.
} 
- $2^{\circ}$ momento: A apresentação dos projetos pelos grupos para a turma, a um mês do final do semestre, com o peso de 15 pontos. Foi um momento em que a professora, os alunos e os tutores-orientadores puderam opinar, apontando contribuições para a melhoria dos projetos;

- $\quad 3^{\circ}$ momento: A elaboração do relatório final do projeto, entregue ao final do semestre, com o peso de 20 pontos, no qual o grupo relatou os resultados, considerando as contribuições apontadas no $2^{\circ}$ momento.

A atuação dos tutores-orientadores estava prevista para depois do $1^{\circ}$ momento. A primeira autora deste artigo atuou como tutora-orientadora de dois grupos: aqueles que aceitaram participar de sua pesquisa ${ }^{6}$ (CAMPOS, 2013), da qual este artigo apresenta parte dos resultados.

Em particular, neste artigo, nossas atenções estão voltadas para o envolvimento de um grupo de estudantes no desenvolvimento do projeto de modelagem, especificamente no decorrer da terceira reunião do grupo. Essa reunião aconteceu em um dia de sábado, no período da manhã. Nesse dia, a lanchonete do ICEx foi o espaço escolhido para o grupo se encontrar e dar andamento ao desenvolvimento do projeto.

Esse grupo era formado por sete estudantes, todos do primeiro período do curso de Gestão Pública. Na referida reunião, estavam presentes cinco dos sete integrantes do grupo, denominados ${ }^{7}$ como Carlos, Catarina, Eduardo, Emanuel e Rodrigo. Além deles, a tutora-orientadora do grupo estava presente na reunião.

O tema escolhido pelo grupo foi A PPP no sistema penitenciário em Minas Gerais. A sigla PPP significa parceria público-privadas, ou seja, de maneira geral, consiste em articulação entre o setor público, empresas e organizações não-governamentais, na qual parte das responsabilidades quanto à administração ou outros serviços, que antes eram assumidos pelo Estado, passam a ser de responsabilidade do setor privado. Em específico, ela está sendo implementada no sistema penitenciário no Brasil pela primeira vez, por iniciativa do governo do Estado de Minas Gerais, para a construção, e posterior administração, de um complexo penitenciário na cidade de Ribeirão das Neves, localizada na região metropolitana de Belo Horizonte. Essa proposta é apresentada pelo Governo de Minas Gerais como uma possibilidade de promover a ressocialização dos detentos. Diante dessa proposta, o grupo teve como objetivo investigar quais as vantagens da implementação da PPP no sistema penitenciário para o Estado de Minas Gerais.

Para o desenvolvimento do trabalho, o grupo definiu uma noção de lucro que correspondia à diferença entre o que o Estado gastaria, no seu atual sistema, para manter o mesmo serviço que será oferecido com a implementação da PPP, e o custo que terá para manter o detento nesse novo sistema, somado a isso o valor que economizará na construção do complexo penitenciário. Embora nessa PPP a construção não seja de responsabilidade do setor privado, o terreno é cedido pelo Estado e, ao fim do contrato, o imóvel pertencerá a ele.

\footnotetext{
${ }^{6}$ Pesquisa de mestrado desenvolvida sob a orientação da segunda autora deste artigo, no âmbito do Programa de Pós-Graduação em Educação, da UFMG.

${ }^{7}$ Utilizaremos nomes fictícios, escolhidos pelos próprios alunos, buscando preservar suas identidades.
} 
Para manter um detento no sistema penitenciário, vários aspectos estão envolvidos, como alimentação, saúde, educação, higiene etc. O grupo, foco de nosso estudo, escolheu abordar a educação, pois, para eles, esse é um aspecto determinante no processo de ressocialização dos detentos. Sobre educação, o grupo esclareceu que se trata, em seu projeto, das modalidades de ensino da Educação Básica e de formação para o trabalho.

Em síntese, o grupo buscou calcular o lucro como o valor que o Estado não precisará dispor para a construção do complexo penitenciário e a diferença do valor entre o que o Estado gastaria para que todos os detentos tivessem acesso a alguma modalidade de ensino, assim como previsto na PPP, e o valor que o Estado gasta atualmente atendendo apenas uma pequena parcela dos detentos em tal demanda.

Os aspectos metodológicos referentes à pesquisa e os procedimentos adotados para seu desenvolvimento trarão melhores esclarecimentos sobre o desenvolvimento do projeto, principalmente sobre o papel da tutoraorientadora. Esses aspectos serão discutidos na próxima seção.

\section{Abordagem metodológica}

Em convergência com o nosso propósito de gerar compreensões sobre o envolvimento dos alunos em uma atividade de modelagem, este estudo é de natureza qualitativa (ALVES-MAZZOTI, 1998; BOGDAN; BIKLEN, 1994).

Os dados apresentados neste artigo são oriundos da filmagem de uma reunião dos cinco estudantes com a tutora-orientadora, assim como das entrevistas realizadas pela pesquisadora com cada aluno, individualmente.

Os procedimentos metodológicos adotados na pesquisa foram ganhando contornos a partir da relação entre os objetivos da pesquisa e as especificidades do contexto do estudo. Tais procedimentos também se adaptaram à organização que a professora da disciplina propôs para o desenvolvimento dos projetos de modelagem.

A orientação presencial da tutora-orientadora ao grupo de alunos propiciou formar o que Barbosa (2007b) denomina espaços de interação, que são os momentos de encontro entre o professor e os alunos e entre os alunos para discutirem a atividade. Na especificidade da atividade em discussão, a tutora-orientadora desempenhou o papel de professora, no entendimento de Barbosa (2007b). Dessa maneira, foram constituídos espaços de negociação (BARBOSA, 2004), que são momentos em que os alunos, juntamente com o professor, negociam sobre os objetivos e os procedimentos para o desenvolvimento da atividade.

Por essa razão, podemos dizer que o procedimento metodológico adotado pela pesquisadora, na reunião com o grupo, foi a observação não-estruturada e participante (ALVES-MAZZOTTI, 1998; VIANNA, 2003). Alves-Mazzotti (1998) explica que, nesse tipo de observação, “os comportamentos a serem observados não são predeterminados, eles são observados e relatados de forma como ocorrem, visando descrever e compreender o que está ocorrendo em uma dada situação" (p. 166). Sobre observação participante, Vianna (2003) afirma que o observador é parte integrante da situação, podendo até contribuir para que a situação aconteça. 
Das observações desenvolvidas no decorrer da pesquisa de campo, emergiram alguns questionamentos que foram abordados nas entrevistas realizadas com os sujeitos. As entrevistas, do tipo semiestruturadas, podem ser caracterizadas a partir de "uma formulação flexível, [nas quais] as sequências e minúcias ficam por conta do discurso dos sujeitos e da dinâmica que acontece naturalmente" (ROSA; ARNOLDI, 2006, p. 31).

Com relação ao tratamento dos dados, dos vídeos, obtidos a partir da filmagem da reunião, foram selecionados três episódios, que serão apresentados na próxima seção. Primeiramente, analisaremos os episódios para entender o que aconteceu. Posteriormente, buscaremos, nas entrevistas, compreensões sobre o que aconteceu a partir das perspectivas dos sujeitos. Em seguida, proporcionaremos um diálogo entre episódios, entrevistas e o referencial teórico

\section{Os episódios e uma análise}

\subsection{Episódio 1: O notebook saiu da cena ${ }^{8}$}

A reunião começou com a presença da tutora-orientadora, do Emanuel e do Rodrigo. O Emanuel pegou todo o material sobre o trabalho que estava com ele e colocou sobre a mesa. Era um material impresso no qual constavam reportagens disponíveis na internet sobre o tema do projeto. Iniciou-se a discussão sobre o tema, relembrando as informações que foram obtidas a partir das duas reuniões anteriores ${ }^{9}$. Naquele momento, ele ligou seu notebook.

(1) Emanuel: Aí a gente vai ter que colocar em cima disso aqui, não é? (põe a mão no material impresso que estava em cima da mesa).

(2) Tutora-orientadora: É, depois que vocês, eu penso que é assim, [...], depois que vocês forem investigando a situação, você vai descrever nesse projeto. Agora a pergunta tem que estar clara, o que é que a gente vai investigar.

(3) Rodrigo: Igual à pergunta da metodologia.

(Gravação em vídeo do $3^{\circ}$ encontro, 01/10/2011)

A preocupação do Emanuel é com a escrita do relatório que será entregue à professora. Ele procura o relatório entre os documentos no notebook e, após o encontrar, afirma:

(4) Emanuel: Justificativa, hipótese, trabalho, eu quero escrever isso aqui [ele fez a leitura dos tópicos do relatório inicial]. É, a gente já poderia ir colocando isso aqui professora [tutora-orientadora], a questão da introdução, porque pra não perder essas ideias aí que você tem bem claras, eu não tenho essa ideia bem clara assim, eu vou ter que ler várias vezes.

(Gravação em vídeo do $3^{\circ}$ encontro, 01/10/2011)

O Emanuel começou a ler o que já estava escrito no relatório:

\footnotetext{
${ }^{8}$ A partir daqui, a palavra cena aparecerá em diversos momentos no texto. Esclarecemos, então, que sentidos são atribuídos a ela, neste artigo. Quando falamos que "o notebook está em cena", nos referimos à mídia utilizada para o desenvolvimento de alguma tarefa do projeto de modelagem, em determinado momento, e essa tarefa depende da utilização de tal mídia. Posteriormente, falaremos em "sujeitos em cena" e "a Matemática em cena". "Sujeitos em cena" refere-se ao sujeito assumindo para si a responsabilidade do desenvolvimento de alguma tarefa do projeto de modelagem, em determinado momento. "A Matemática em cena" significa que a principal tarefa em desenvolvimento pelo grupo, no referido momento, é a matematização.

${ }^{9}$ O Rodrigo participou das duas reuniões anteriores e o Emanuel participou somente da primeira.
} 
(5) Emanuel: Então, o presente trabalho, a introdução seria: o presente trabalho [...].

(6) Tutora-orientadora: Eu só acho que está faltando, o que eu acho que está faltando, até mesmo para o grupo, é chegar à situação, investigar a situação pra depois...

(7) Emanuel: Começar aqui.

(8) Tutora-orientadora: Eu acho que é um caminho, porque assim, vocês estão passando um tempo, muito no relatório e não estão investigando em si.

(Gravação em vídeo do $3^{\circ}$ encontro, 01/10/2011)

No mesmo momento da fala (8), o Emanuel fechou o notebook, reorganizou os papéis na mesa e respondeu:

(9) Emanuel: Isso é verdade, pois é, então essa investigação tem que partir.

(10) Tutora-orientadora: Vamos gente, meter a mão na massa.

(Gravação em vídeo do $3^{\circ}$ encontro, 01/10/2011)

O Emanuel começou a mexer nos papéis procurando informações. Ao mesmo tempo, o Rodrigo se comunicava pelo celular com outros integrantes do grupo, que ainda não tinham chegado: o Eduardo e a Fernanda $^{10}$. O Rodrigo queria saber com quem estavam as anotações feitas sobre as reuniões anteriores.

(11) Tutora-orientadora: Cadê o lápis e a caneta? Vamos lá!

(12) Emanuel: Também?

(13) Tutora-orientadora: Ah, vamos chegar a isso aí gente.

(14) Rodrigo: Ah, tá com o Eduardo, o caderno está vindo já.

(Gravação em vídeo do $3^{\circ}$ encontro, 01/10/2011)

Nesse momento, o Emanuel pegou uma caneta e a tutora-orientadora ajeitou uma folha de papel à sua frente, para as anotações.

A partir desse episódio, é possível entender que tanto o Emanuel quanto o Rodrigo não estavam familiarizados com o que o grupo tinha desenvolvido nas reuniões anteriores. O Emanuel estava preocupado com o relatório e o Rodrigo em descobrir com quem estavam as anotações das reuniões anteriores, mas nenhum deles tinha ainda um papel definido no grupo.

\subsection{Episódio 2: O notebook retorna à cena}

Após o momento descrito no episódio 1, o Emanuel começou a escrever as informações consideradas importantes, que emergiam da discussão. Os outros integrantes foram chegando: primeiro a Catarina, depois o Eduardo e, por último, o Carlos. A discussão prosseguiu e, a cada integrante que chegava, o grupo tratava de familiarizá-lo com o que estava sendo discutido.

O Emanuel continuou assumindo a responsabilidade de registrar as informações importantes, inclusive as informações matemáticas, enquanto todos discutiam. Essa situação permaneceu até surgir, na discussão, um comentário sobre informações que foram enviadas por e-mail pela Fernanda, que não estava presente na reunião, momento que será descrito abaixo:

\footnotetext{
${ }^{10}$ Fernanda era uma das integrantes do grupo, mas ela não participou da reunião à qual este artigo se refere. Entretanto, como membro do grupo, ela tinha participado das duas reuniões anteriores e detinha informações sobre o desenvolvimento do projeto.
} 
(15) Catarina: Aí coloca, abre um parêntese aí, vê se a gente consegue investigar quanto seria o valor de uma construção de um presídio.

(16) Carlos: A Fernanda olhou pelo Google [na reunião anterior], 16 milhões, trilhões, 16 milhões para um presídio de 400 vagas.

(17) Emanuel: É, foi alguma coisa assim mesmo.

(18) Eduardo: É muito dinheiro.

(19) Tutora-orientadora: Não esquece de pegar as fontes, se não...

(20) Catarina: É, coloca aí oh Rodrigo.

(21) Rodrigo: Ela mandou por e-mail, para o meu e-mail, todo mundo recebeu.

(Gravação em vídeo do $3^{\circ}$ encontro, 01/10/2011)

Quando surgiu a dúvida sobre o e-mail da Fernanda, o Emanuel abriu o notebook novamente. Coincidentemente, naquele mesmo momento, o grupo teve que sair da lanchonete porque já havia encerrado o expediente ${ }^{11}$, dando início a um momento itinerante:

(22) Emanuel: Fechou mesmo Catarina?

(23) Catarina: Então, vamos gente, vamos.

(24) Tutora-orientadora: Vamos para um outro lugar!

(25) Rodrigo: Aqui em baixo, ué!

(Gravação em vídeo do $3^{\circ}$ encontro, 01/10/2011)

Todos saíram andando pelo ICEx à procura de um lugar para continuar a reunião. Encontrando uma sala de aula vazia e com a porta aberta, todos buscaram se organizar e retomar a atividade. O novo espaço deu origem a uma organização diferente. Nos primeiros momentos dessa reunião, quando o grupo estava reunido na lanchonete do ICEx, todos os participantes da atividade estavam em volta de uma mesma mesa. A sala de aula tinha várias carteiras individuais, quadro e giz, o que ajudou a mudar a organização dos participantes. Ao chegarem à sala de aula, eles se localizaram espacialmente espalhados pela sala, de maneira aproximada a um semicírculo. Dentre eles, o Emanuel procurou sentar-se em uma carteira próxima a uma tomada, para carregar a bateria do notebook.

A reunião recomeçou e o Carlos queria verificar qual o valor da construção de um presídio:

(26) Carlos: Você tem acesso à internet aí Emanuel? Só pra nós... Pra ver se encaixa os valores aqui.

(Gravação em vídeo do $3^{\circ}$ encontro, 01/10/2011)

O Carlos, ao fazer essa pergunta para o Emanuel, responsabilizou seu colega por buscar as informações que só seriam possíveis de serem obtidas por meio do acesso à internet. De todos os integrantes do grupo, somente o Emanuel levava o notebook para as reuniões. Então, ele, mostrando satisfação, reassume a responsabilidade de utilizar seu notebook.

Neste episódio, vimos que o papel do Emanuel na atividade vai sendo definido e que isso estava intimamente relacionado à presença do seu notebook e ao fato de ele ser o único integrante do grupo a levar tal mídia para a reunião.

\subsection{Episódio 3: A Matemática aparecendo: alguém assume a cena?}

\footnotetext{
${ }^{11}$ Aos sábados, a lanchonete do ICEx encerra o expediente às 11 horas.
} 
A discussão continuou. Em particular, o Emanuel assumiu a responsabilidade de buscar informações, mediado pelo seu notebook. Mesmo se concentrando nessa função, ele participava da discussão. Mas não retomou o registro das anotações, como no momento anterior à mudança de espaço.

Nos primeiros momentos, após o reinício da reunião, a discussão envolveu o lucro que o Estado teria ao se comparar os dois modelos, o público e o da PPP, quanto ao valor gasto com acesso à Educação dos detentos. Naqueles momentos, surgiram várias interpretações matemáticas, mas nenhum dos alunos anotava as informações. O Emanuel já estava assumindo outra responsabilidade. Em alguns momentos, a tutora-orientadora relembrava a necessidade de fazer algum tipo de anotação:

(27) Tutora-orientadora: De maneira geral como é que a gente pode escrever isso?

(28) Tutora-orientadora: Vamos tentar colocar isso matematicamente aí.

(Gravação em vídeo do $3^{\circ}$ encontro, 01/10/2011)

O Emanuel estava utilizando o notebook no momento da fala (28) da tutora-orientadora, e, logo após, ele ressalta a tarefa pela qual ele estava se responsabilizando naquele momento:

(29) Emanuel: Estou tentando achar o[...][refere às informações sobre o valor da construção do presídio].

(Gravação em vídeo do $3^{\circ}$ encontro, 01/10/2011)

Em um momento posterior a essa fala do Emanuel, a Catarina demonstrou que estava entendendo a discussão e falou, claramente para o grupo, como expressar matematicamente a situação:

(30) Catarina: Então, a gente pode colocar o cento e oitenta multiplicado por [...].

(31) Tutora-orientadora: Exatamente, vamos colocar isso aí.

(Gravação em vídeo do $3^{\circ}$ encontro, 01/10/2011)

Esse valor de cento e oitenta, mencionado pela Catarina, é referente ao custo que o Estado alegava ter, mensalmente, no ano de 2010, com a Educação de cada detento que tinha acesso às atividades que o grupo entendia como a Educação dos presidiários no sistema penitenciário público. A discussão continuou como transcrita a seguir.

(32) Carlos: Se eu não colocar no quadro, [...].

(33) Rodrigo: Tem que colocar no quadro.

(34) Emanuel: A Catarina que é melhor nisso aí.

(35) Carlos: Se eu não colocar ali no quadro, ali, porque eu não pego nada de primeira mão não, sô.

(36) Tutora-orientadora: Mas, eu não posso escrever por vocês. Quem tem que construir o modelo são vocês.

(Gravação em vídeo do $3^{\circ}$ encontro, 01/10/2011)

Depois disso, o Carlos resolveu escrever no quadro. Mas, expressou a necessidade da participação da tutora-orientadora, o que pode ser entendido na primeira frase que ele disse ao começar escrever no quadro.

(37) Carlos: Segundo nossa querida orientadora baiana ...

(Gravação em vídeo do $3^{\circ}$ encontro, 01/10/2011)

A reunião prosseguiu com o Carlos escrevendo no quadro as informações matemáticas que o grupo estava discutindo no processo de matematização ${ }^{12}$ da situação. A Catarina e o Eduardo passaram a orientar o Carlos sobre

\footnotetext{
${ }^{12}$ Apoiadas em Freitas (2013), entendemos por matematização o processo que inclui a organização dos dados visando à utilização de ferramentas matemáticas para explorá-los, utilizando a simbologia apropriada à questão investigada.
} 
o que ele escrevia, os outros integrantes também participavam. Mas, as decisões sobre o que o Carlos escrevia eram compartilhadas, principalmente, pela tutora-orientadora, a Catarina e o Eduardo.

A descrição desse episódio nos traz informações de quais dos cinco alunos, que estavam presentes, assumiram a cena, espontaneamente, quando a Matemática aparecia no desenvolvimento do trabalho: a Catarina, o Carlos e o Eduardo; e quais dos alunos buscaram não interferir ou interferir pouco naqueles momentos: o Rodrigo e o Emanuel.

\subsection{Análise inicial dos episódios: entendendo as possibilidades de ação a partir da relação com o saber}

A nossa compreensão, a partir desses episódios, é que aconteceram diferentes tipos de envolvimento dos alunos de acordo com diferentes funções nas quais eles percebiam ser possível atuar ao longo do desenvolvimento do projeto de modelagem. Chamou-nos a atenção, em particular, a mudança das funções assumidas por dois alunos: o Emanuel e o Carlos. Vamos nos ater ao envolvimento dos dois.

Emanuel assumiu a função de relator do projeto e, ao ser convidado pela tutora-orientadora [falas (6) e (8)] a assumir alguma função referente à matematização da situação tratada no projeto, não se envolveu muito. Sentiuse confortável e, talvez, até aliviado, quando foi solicitado pelo grupo, especificamente pelo Carlos, a retomar o uso do notebook [fala (26)]. Carlos, por sua vez, embora não tivesse, inicialmente, alguma função referente à matematização, se prontificou a assumir tal função [fala (37)], mesmo depois de o Emanuel ter designado tal função à Catarina [fala (34)]. Dessa análise, podemos perceber que o Emanuel procurou sair da cena e o Carlos resolveu atuar quando a Matemática entrava em cena, ou seja, no momento da matematização.

Esses envolvimentos podem ser fruto, dentre outras coisas, do que os alunos consideram como sendo possível para eles fazerem em tal atividade. Nessa direção, discutiremos o envolvimento desses alunos nessa atividade de modelagem a partir da noção de possibilidades de ação.

Inicialmente, estamos conceituando possibilidades de ação como aquilo que os alunos vislumbram como possível de atuar quando estão desenvolvendo uma atividade de modelagem. Nesse sentido, as possibilidades de ação são individuais, ou seja, cada aluno a percebe de maneira diferente.

Os diferentes envolvimentos do Emanuel e do Carlos, amparados por mudanças de suas respectivas funções, levaram-nos a questionar sobre quais as razões dos alunos para entrar ou sair de cena quando a Matemática entrava em cena. Parece-nos, portanto, que a análise de mudanças de funções pode nos trazer subsídios para a compreensão das possibilidades de ação.

Apresentamos, a seguir, alguns trechos das entrevistas que esclarecem tais razões. Eles fazem parte das respostas dos alunos à pergunta que, de maneira geral, pode ser escrita da seguinte forma: Como você descreve seu envolvimento no projeto no momento da matematização? 
Eu via assim que [os cálculos] eram bem claros, tudo que estava sendo colocado ali era fácil. A participação, acho que de todos, dando opinião para formular aquele cálculo porque estava bem compreendido, acho pela grande maioria. Então, meu envolvimento foi mesmo de estar ajudando a todos.

(Emanuel, Entrevista, 28/11/2011)

[...] na hora que entrou a parte matemática, pela minha dificuldade em Matemática, eu preferia optar por um colega que tivesse mais identificação pra poder acompanhar o raciocínio dele e ali poder participar. Como eu vi, em determinados momentos, que eu queria ter uma atitude mais ativa, eu fui para o quadro, né? Fui tentar escrever lá no quadro, lá, fui tentar compreender melhor.

(Carlos, Entrevista, 21/11/2011)

No trecho acima, o Emanuel explicou que sua ação foi a de acompanhar o desenvolvimento do processo de matematização, mas não buscou atuar no processo, e sim, entender o que estava sendo feito. Na entrevista, ele descreveu sua relação com a matemática, em sua trajetória, da seguinte maneira: É decepcionante, né, e a gente vê isso agora porque, eu vejo assim, eu acho que tenho culpa nisso, a família tem culpa, mas o professor também tem muita culpa [...]. (Emanuel, Entrevista, 28/11/2011)

Ao relacionarmos esses trechos da entrevista com a fala (34) do Emanuel, na qual ele afirma que a Catarina teria mais condições de assumir a matematização, compreendemos que ele sente suas possibilidades de ação limitadas naquela função, devido à sua relação com a Matemática. Ou seja, para ele, como a maioria do grupo estava compreendendo os cálculos, ele poderia não se envolver nessa parte.

No caso do Carlos, nossa análise, do trecho da entrevista, sugere-nos que ele, no momento da matematização, encontrava-se entre duas ações: a de esperar que um colega assumisse a cena, por causa de sua dificuldade com a Matemática, e a de ele mesmo assumir a cena, para entender o que estava sendo feito.

A partir disso, podemos compreender que a relação do Carlos com a Matemática, por um lado, posicionouo fora da cena quando a Matemática entrava em cena. Essa nossa compreensão é alimentada, também, por um trecho da entrevista com o Eduardo: [...] o que o Carlos até me incumbiu, no início, que ele até falou comigo, era a parte da Matemática que não entrava ele (Eduardo, Entrevista, 03/11/2011). Por outro lado, a própria dificuldade com a Matemática colocava o Carlos em cena quando a Matemática entrava em cena, porque ele se envolvia na tentativa de aprender. Na entrevista, ele esclarece seu interesse em aprender Matemática:

Mas, estou na área de Gestão Pública tendo em vista esse desafio da Matemática. O que me motiva é compreender, é a minha última tentativa de ser feliz com a Matemática, sabendo a fundamental importância dela para o curso, o diferencial do curso é a Matemática, quem domina ela. Eu não estou muito feliz com ela não, mas eu sou persistente. (Carlos, Entrevista, 21/11/2011)

Então, a partir da análise que apresentamos nesta seção, entendemos que a relação dos alunos com a Matemática pode influenciar, ou mesmo ter um papel importante, na forma como os alunos vislumbram suas possibilidades de ação no desenvolvimento de atividades de modelagem. Essa análise é um primeiro passo para a construção desse conceito, já que acreditamos que seja necessário analisar que outros fatores podem fazer parte, modificar ou gerar novas possibilidades de ação. Neste artigo, entretanto, nos restringiremos a discutir as possibilidades de ação a partir da relação com o saber (CHARLOT, 2000). Nessa direção, é nosso propósito, na próxima seção, analisar os casos do Emanuel e do Carlos. 


\section{Os casos do Emanuel e do Carlos}

Analisando os envolvimentos do Emanuel e do Carlos, compreendemos que, inicialmente, os dois percebiam que suas possibilidades de ação eram limitadas quando a Matemática entrava em cena. Isso devido às suas próprias percepções sobre suas relações com a Matemática, que foram constituídas não só na experiência que estava sendo vivenciada naquele momento, mas, também, a partir de suas experiências anteriores. Entendemos que essa percepção inicial refere-se à relação de cada um com eles mesmos (CHARLOT, 2000), quando confrontados com uma situação que demandava lidar com conhecimentos matemáticos. Utilizando os conceitos de Charlot (2000), podemos dizer que a atividade de modelagem se caracterizou como conjuntos de significados diferentes para cada um deles.

A análise do episódio 1 nos levou a compreender que, nessa reunião, o Emanuel iniciou sua participação como o escritor do relatório do grupo. Mas, a partir das falas (2), (6) e (8) da tutora-orientadora, ele passou a atuar como o responsável pelo processo de matematização. Cabe destacar que, naquele momento, dos componentes do grupo, somente o Emanuel e o Rodrigo estavam presentes. Além disso, as falas da tutora-orientadora podem ser entendidas como ações para interromper uma determinada ação, parte do projeto, que estava sendo desenvolvida pelo Emanuel, cujo tempo para realização poderia ser um momento futuro, visto que dependia de resultados que ainda não tinham sido obtidos.

O Emanuel mudou de função pela segunda vez quando surgiu a dúvida sobre o e-mail enviado pela Fernanda, no episódio 2. Então, ele se responsabilizou pela busca por esclarecimentos sobre o e-mail e abandonou a função anterior. A nova função do Emanuel foi legitimada pelo Carlos quando o solicitou, na fala (26), que buscasse as informações sobre o valor da construção de um presídio.

Nas falas (29) e (34), do Emanuel, ele buscou explicitar para o grupo que não tinha interesse em atuar no processo de matematização: na fala (29), ele explicitou que estava atuando, naquele momento, na pesquisa das informações sobre o valor da construção do presídio e, na fala (34), disse existir uma pessoa, entre eles, mais habilitada para tal função, que era a Catarina.

A mudança das funções exercidas pelo Emanuel tem a ver com a relação dele com os outros sujeitos (CHARLOT, 2000) envolvidos na atividade: autoridade exercida pela orientadora, a legitimidade que o Carlos deu à função de Emanuel de buscar informações na internet e como ele percebia as capacidades das outras pessoas se comparadas às dele, no caso específico da Catarina, quando referia ao conhecimento matemático.

O Carlos assumiu, no episódio 3, o processo de matematização das informações, a partir da ação de escrevê-las no quadro. Dessa forma, entendemos que, naquele momento, ele mudou de função em relação as suas responsabilidades na atividade, já que antes ele estava, apenas, participando oralmente das discussões.

Bolema, Rio Claro (SP), v. 29, n. 51, p. 167-182, abr. 2015 
As falas (27), (28), (31) e (36) da tutora-orientadora podem ter significado um convite para que o Carlos entrasse em cena no processo de matematização. Esse convite foi aceito por ele a partir de sua necessidade de criar possibilidades para entender o que estava sendo discutido. Nas falas (35) e (37), ele explicitou a importância de ver as informações escritas como determinantes para sua compreensão. Mas, foi somente depois da fala (36), na qual a tutora-orientadora esclareceu que não assumiria a responsabilidade pelo processo de matematização, que o Carlos assumiu a cena.

A relação com os outros (CHARLOT, 2000) também foi decisiva na mudança de funções vivida por Carlos: a postura do Emanuel, de não assumir a matematização, a autoridade da tutora-orientadora e, de forma não explícita, o incentivo dos demais colegas (por exemplo, Catarina, na fala (30), dá uma pista sobre como dar prosseguimento à matematização) funcionaram como impulsionadores dessa mudança.

A partir dessa análise, consideramos que, para o Emanuel, a referida atividade de modelagem se caracterizou como um conjunto de significados (CHARLOT, 2000) que não o favoreceu a participar confortavelmente da atividade quando a Matemática entrava em cena. No caso do Carlos, possibilitou que ele passasse a atuar no processo de matematização da situação em estudo.

\section{Envolvimento dos alunos em atividades de modelagem, possibilidades de ação e relação com o saber: considerações finais}

Nosso objetivo, neste artigo, foi compreender o envolvimento de dois alunos, integrantes de um grupo, em uma atividade de modelagem matemática, a partir de suas relações com o saber matemático. Para tal, criamos o conceito de possibilidades de ação vislumbradas pelos alunos em atividades de modelagem e o discutimos, inicialmente, tendo por referência a relação com o saber (CHARLOT, 2000).

A natureza de atividades de modelagem possibilita que os alunos atuem em diferentes funções. Por um lado, isso parece representar uma divisão de tarefas, o que nem sempre é desejável em atividades desse tipo. Por outro, pode oferecer aos alunos um maior número de possibilidades de ação e, consequentemente, pode nos fornecer informações mais ricas sobre o envolvimento dos alunos em atividades que demandam conhecimentos matemáticos.

Diante disso, consideramos pertinente questionar o que significa dizer que os alunos se envolveram ou não em uma atividade de modelagem. A partir da análise que fizemos, o envolvimento dos alunos poderia ser compreendido não apenas como as ações efetivamente assumidas pelos alunos, mas também pelas possibilidades de ação vislumbradas por eles. As mudanças de funções assumidas pelos alunos possibilitaram que tais níveis de ações fossem percebidos.

Essas mudanças, por sua vez, sugerem que o envolvimento, em atividades de modelagem, pode modificar a relação que cada aluno estabelece com o saber matemático. Não estamos afirmando que serão sempre mudanças 
positivas. Portanto, entendemos que compreender as possibilidades de ação dos alunos é algo que pode contribuir para os professores interferirem positivamente no desenvolvimento de atividades dessa natureza. Além disso, embora não tenha sido o propósito neste artigo, pudemos perceber que alguns fatores são geradores de mudanças nas ações dos alunos, e que podem interferir, e até mesmo modificar, as possibilidades de ação dos alunos em atividades de modelagem. Neste caso em estudo, percebemos que a presença de diferentes mídias e a interferência da tutora-orientadora tiveram papéis importantes para tais mudanças.

O referencial da relação com o saber de Charlot (2000) nos possibilitou perceber que o envolvimento dos alunos em atividades de modelagem sofre influência de fatores que não necessariamente se relacionam às condições propostas para a realização e condução desse ambiente de aprendizagem (SKOVSMOSE, 2000), ao que efetivamente acontece nos ambientes de modelagem. Ou seja, faz-se necessário buscar compreender fatores que extrapolam as condições momentâneas, demanda-se compreender que outros fatores desencadeiam as ações dos sujeitos nesses ambientes de aprendizagem, tais como, aspectos de sua história de vida e os seus desejos futuros.

Como não é nosso propósito esgotar essa discussão neste artigo, agendamos, para um próximo momento, a discussão sobre fatores geradores de mudanças nas possibilidades de ação dos alunos em atividades de modelagem e quais são as possíveis implicações favorecidas por essas mudanças.

\section{Agradecimentos}

Embora não sejam responsáveis pelas ideias aqui apresentadas, gostaríamos de agradecer aos alunos e professoras da linha Educação Matemática, do Programa de Pós-Graduação em Educação, da UFMG, por comentários feitos a uma versão preliminar deste artigo. Em particular, agradecemos a leitura cuidadosa, críticas e sugestões feitas por Viviane Ribeiro de Souza Cabral, à época, aluna de doutorado da referida linha. Agradecemos, também, o apoio financeiro concedido pelo Conselho Nacional de Desenvolvimento Científico e Tecnológico $(\mathrm{CNPq})$ à primeira autora, para a realização de sua pesquisa de mestrado.

\section{Referências}

ALVES-MAZZOTTI, A. J. O método nas ciências sociais. In: ALVES-MAZZOTTI, A.; GEWANDSZNAJDER, F. (Org..). O método das ciências naturais e sociais: pesquisa quantitativa e qualitativa. 2. ed. São Paulo: Pioneira, 1998. p. 147-178.

ARAÚJO, J. de L. Cálculo, Tecnologias e Modelagem Matemática: as discussões dos alunos. 2002. 173f. Tese (Doutorado em Educação Matemática) - Instituto de Geociências e Ciências Exatas, Universidade Estadual Paulista, Rio Claro, 2002.

ARAÚJO, Jussara de Loiola; BARBOSA, Jonei Cerqueira. Face a face com a modelagem matemática: como os alunos interpretam essa atividade? Bolema - Boletim de Educação Matemática, Rio Claro, v. 23, n. 23, p. 79-95, 2005.

BARBOSA, J. C. Modelagem matemática em cursos para não-matemáticos. In: CURY, H. N. (Org.). Disciplinas matemáticas em cursos superiores: reflexões, relatos e propostas. Porto Alegre: EDIPUCRS, 2004. p. 63-83. 
BARBOSA, J. C. A prática dos alunos no ambiente de modelagem matemática: o esboço de um framework. In: BARBOSA, J. C.; CALDEIRA, A. D. e ARAÚJO, J. L. (Org.). Modelagem Matemática na Educação Matemática Brasileira: pesquisas e práticas educacionais. Recife: SBEM, 2007a. p. 161-174.

BARBOSA, J. C. Teacher-student interactions in mathematical modelling. In: HAINES, C., et. al. (Ed.). Mathematical Modelling: education, engineering and economics (ICTMA12). Chichester: Horwood Publishing, 2007b. p. 232-240.

BOGDAN, R.; BILKEN, S. Investigação qualitativa em educação: uma introdução à teoria e aos métodos. Porto: Porto Editora, 1994.

CAMPOS, I. da S. Alunos em ambientes de modelagem matemática: caracterização do envolvimento a partir da relação com o background e o foreground. 2013. 203f. Dissertação (Mestrado em Educação) - Faculdade de Educação, Universidade Federal de Minas Gerais, Belo Horizonte. 2013.

CHARLOT, B. Da relação com o saber: Elementos para uma teoria. Tradução de Bruno Magne. Porto Alegre: Artes Médicas Sul, 2000.

FREITAS, W. S. A matematização crítica em projetos de modelagem. 2013. 260f. Tese (Doutorado em Educação) Faculdade de Educação, Universidade Federal de Minas Gerais, Belo Horizonte. 2013.

KAISER, G.; SRIRAMAN, B. A global survey of international perspectives on modelling in mathematics education. The International Journal on Mathematics Education, v. 38, n. 3, p. 302-310, jun. 2006.

MAAß, K. Barriers and opportunities for the integration of modeling in mathematics classes: results of an empirical study. In: BLOMHOJ, M.; BRANDELL, G.; NISS, M. (Eds.). Teaching mathematics and applications: the $10^{\text {th }}$ ICME. Compenhagen: Springer, 2005. p. 61-74.

OLIVEIRA, A. M. P. de; BARBOSA, J. C.; SANTANA, T. S. Modelagem matemática na sala de aula: Uma compreensão acerca da resistência dos alunos. In: SIMPÓSIO INTERNACIONAL DE PESQUISAS EM EDUCAÇÃO MATEMÁTICA, 4., 2009, Brasília, Anais, Brasília: SBEM. 2009. 1 - 21.

ROSA, M. V. F. P. do C.; ARNOLDI, M. A. G. C.. A entrevista na pesquisa qualitativa: mecanismo para validação dos resultados. São Paulo: Autêntica, 2006.

VIANNA, H. M. Pesquisa em Educação: A observação. Brasília: Editora Plano, 2003.

SKOVSMOSE, O. Cenários para investigação. Bolema - Boletim de Educação Matemática, Rio Claro, v. 13, n. 14, p. 6691, 2000.

Submetido em Abril de 2014. Aprovado em Julho de 2014. 